\title{
Assessing the effects of the clumping phenomenon on BRDF of a maize crop based on 3D numerical scenes using DART model
}

\author{
Sylvie Duthoit ${ }^{a, b, *}$, Valérie Demarez ${ }^{a}$, Jean-Philippe Gastellu-Etchegorry ${ }^{a}$, \\ Emmanuel Martin ${ }^{a, c}$, Jean-Louis Roujean ${ }^{d}$ \\ ${ }^{a}$ CESBIO, 18, Avenue Edouard Belin, 31401 Toulouse Cedex 9, France \\ ${ }^{\mathrm{b}}$ University of Johannesburg, Department of Botany, PO Box 524, Auckland Park 2006, Johannesburg, South Africa \\ ${ }^{\mathrm{c}}$ Magellium, 24, rue Hermès BP 12113, 31521 Ramonville Saint-Agne, France \\ ${ }^{\mathrm{d}}$ CNRM/GAME, Météo-France/CNRS, 42, Avenue G. Coriolis, 31057 Toulouse Cedex, France
}

\section{A R T I C L E I N F O}

Article history:

Received 21 July 2007

Received in revised form

29 January 2008

Accepted 28 March 2008

Keywords:

Maize canopy

Clumping

Bidirectional Reflectance

Distribution Function (BRDF)

Discrete Anisotropic Radiative

Transfer model

Leaf area index (LAI)

\begin{abstract}
A B S T R A C T
Inverting radiative transfer $(\mathrm{R}-\mathrm{T})$ models against remote sensing observations to retrieve key biogeophysical parameters such as leaf area index (LAI) is a common approach. Even if new inversion techniques allow the use of three-dimensional (3D) models for that purpose, onedimensional (1D) models are still widely used because of their ease of implementation and computational efficiency. Nevertheless, they assume a random distribution of foliage elements whereas most canopies show a clumped organization. Due to that crude simplification in the representation of the canopy structure, sizeable discrepancies can occur between 1D simulations and real canopy reflectance, which may further lead to false LAI values. The present investigation aims to appraise to which extent the incorporation of a clumping index (noted $\lambda$ ) into 1D R-T model could improve the simulations of Bidirectional Reflectance Distribution Function (BRDF). Canopy BRDF is simulated here for three growth stages of a maize crop with the Discrete Anisotropic Radiative Transfer (DART) model in the visible and near infrared spectral bands, for two contrasted soil types (dark and bright) and different levels of heterogeneity to represent the canopy structure. 3D numerical scenes are based on in-situ structural measurements and associated BRDF simulations are thus considered as references. 1D scenarios assume either that leaves are randomly distributed $(\lambda=1)$ or clumped $(\lambda<1)$. If BRDF simulations seem globally reliable under the assumption of a random distribution in near infrared, it can also lead to relative errors on the total BRDF up to $30 \%$ in the red spectral band. It comes out that the use of a clumping index in a $1 \mathrm{D}$ reflectance model generally improves BRDF simulations in the red considering a bright soil, which seems relatively independent of LAI. In the near infrared, best results are usually obtained with homogeneous canopies, except with the dark soil. Clearly, influent factors are mainly the LAI and the spectral contrast between soil and leaves.
\end{abstract}

(C) 2008 Elsevier B.V. All rights reserved.

\footnotetext{
* Corresponding author at: CESBIO, 18, avenue Edouard Belin, bpi 2801, 31401 TOULOUSE cedex 9, France. Tel.: +33 561558536 ; fax: +33561558500.

E-mail addresses: sylvie.duthoit@gmail.com (S. Duthoit), demarez@cesbio.cnes.fr (V. Demarez), gastellu@cesbio.cnes.fr (J.-P. Gastellu-Etchegorry), emmanuel.martin@magellium.fr (E. Martin), jean-louis.roujean@meteo.fr (J.-L. Roujean). 0168-1923/\$ - see front matter (C) 2008 Elsevier B.V. All rights reserved. doi:10.1016/j.agrformet.2008.03.011
} 


\section{Introduction}

Leaf area index (LAI) is a key biophysical parameter for the modeling of terrestrial carbon and water fluxes exchanges. For such a reason, the mapping of LAI at an appropriate spatial scale has become an increasing matter of interest (Morisette et al., 2006). In this context, remote sensing observations yield the unique mean to ensure timely information on vegetation canopy at a global scale. Several methods and techniques have been implemented for a LAI retrieval based on the available satellite information. Basically, it relies on the inversion of radiative transfer $(\mathrm{R}-\mathrm{T})$ models that allow simulating the top of canopy (TOC) Bidirectional Reflectance Distribution Function (BRDF) (Bicheron and Leroy, 1999; Goel and Strebel, 1983; Jacquemoud et al., 2000; Kuusk, 1994; Pinty, 1990; Privette et al., 1994; Roujean and Breon, 1995; Weiss et al., 2000). The accuracy assessment of the LAI estimate depends on the quality of the radiometric information (e.g., multi-angular satellite data) and on the reliability of the inverted model. Onedimensional (1D) canopy R-T models such as the widespread Scattering by Arbitrary Inclined Leaves model (SAIL, Verhoef, 1984) are amongst the more commonly used because of their ease of implementation and computational efficiency (Kallel et al., 2007; Lauvernet et al., 2008). However, they fail to correctly represent most vegetation canopies that are usually characterized by various levels of clumping (shoots, branches, individual plants and groups of plants). New inversion techniques based on a pre-computed reflectance database such as neural network (Baret et al., 2007; Weiss et al., 2000; Kimes et al., 2002) or look-up tables (LUT, Knyazikhin et al., 1998; Weiss and Baret, 1999; Gastellu-Etchegorry et al., 2003) allow now the use of more realistic three-dimensional (3D) models for exploiting remote sensing data provided by sensors such as MODIS (Myneni et al., 1997; Knyazikhin et al., 1998) or MISR (Knyazikhin et al., 1998; Hu et al., 2007). However, compared to 1D models, 3D models are much more computer intensive and require a more extensive parameterization. This explains why 1D models are still operationally used to retrieve LAI as it is the case with MERIS (Bacour et al., 2006) and also CYCLOPES (Baret et al., 2007) that has shown very good performance for LAI retrieval (Weiss et al., 2007). Thus, there is still a need to improve LAI retrieval using the inversion of 1D R$\mathrm{T}$ models, specifically for heterogeneous vegetation covers.

In that context the potentiality of using a clumping index (noted $\lambda$ hereafter) in 1D models to better simulate BRDF of heterogeneous canopies is explored in that paper. Indeed, it has been shown that using a clumping index in a modified expression of the Poisson model that describes the mutual dependence of leaves position (Monsi and Saeki, 1953; Nilson, 1971; Welles and Norman, 1991) allows a better description of the directional gap fraction in canopies with aggregative structures (Baldocchi and Collineau, 1994; Chen and Black, 1992; Jonckheere et al., 2004; Lemeur and Blad, 1974; Nilson, 1971). Kuusk (1995) also noted that the use of a clumping index improved the modeling of near infrared (NIR) BRDF of Gramineae canopies, and finally led to better LAI estimates.

This work aims to assess the effects of the clumping phenomenon on BRDF simulations of a row crop canopy and to quantify how the use of a clumping index $\lambda$ improves $1 \mathrm{D}$ simulations. For that, the Discrete Anisotropic Radiative
Transfer (DART) model (Gastellu-Etchegorry et al., 1996, $1999,2004)$ is used, first to estimate the directional zenithal variation of the clumping index at three different growth stages and then to simulate the vegetation BRDF. For each stage, different numerical scenes corresponding to different levels of heterogeneity are simulated. Canopy architecture was measured in the field for a maize crop located in South West of France. For 1D turbid models, the architecture is simply described by LAI and leaf angle distribution (LAD), with randomly distributed $(\lambda=1)$ or clumped $(\lambda<1)$ leaves. Simulations are conducted with two types of soils - highly and poorly reflective -, two spectral bands - red and near infrared - and various geometries of illumination. The 3D simulated BRDF simulations are used as references for evaluating 1D simulations.

\section{Methods}

\subsection{Description of the DART model}

\subsubsection{General features}

The DART model (www.cesbio.ups-tlse.fr/us/dart.htm) simulates $\mathrm{BRDF}$, remote sensing images and the spectral radiation budget of 3D natural (e.g., trees, roads, grass, soil, water) and urban landscapes in the visible and short wave infrared domains (Gastellu-Etchegorry et al., 1996). DART has been used in numerous scientific works (Demarez et al., 2000; Guillevic and Gastellu-Etchegorry, 1999; Pinel and GastelluEtchegorry, 1998) and tested against in-situ and remotely sensed measurements of vegetation canopies reflectance (Gastellu-Etchegorry et al., 1999; Malenovský et al., 2008), as well as other 3D reflectance models in the frame of the RAdiation transfer Model Intercomparison (RAMI) exercise (Pinty et al., 2001, 2004; Widlowski et al., 2007). DART and SAIL models give similar results if they are applied to $1 \mathrm{D}$ turbid scene (Demarez, 1997; Martin, 2006).

DART uses the exact kernel and discrete ordinate methods for simulating $\mathrm{R}-\mathrm{T}$ in $3 \mathrm{D}$ landscapes: radiation propagates in a finite number of directions $\left(\Omega_{\mathrm{i}}\right)$ characterized by a zenith angle $\theta_{\mathrm{i}}$ and an azimuth angle $\varphi_{\mathrm{i}}$. It proceeds following an iterative approach: radiation intercepted during an iteration is scattered in the following iteration. It is adapted to any spectral band from the ultraviolet up to the thermal infrared (GastelluEtchegorry et al., 2004). A single DART simulation can provide both 3D scene radiation budget and multi-spectral and multidirectional remote sensing images at any altitude in the atmosphere (Gascon, 2001). Herein, the focus is put on BRDF simulations in the red and NIR spectral bands.

Any landscape is simulated as a rectangular matrix of parallelepiped cells $(\Delta \mathrm{X}, \Delta \mathrm{Y}, \Delta \mathrm{Z})$ which is a building block for simulating infinite scenes: a ray that exits the scene re-enters the scene through the symmetrical face of the scene. Simulated landscapes can be urban or natural, possibly with topography and atmosphere. Vegetation canopies are simulated as the juxtaposition of turbid leaf cells characterized by their leaf volume density, leaf angle distribution and optical properties (reflectance and transmittance). Soil surfaces are simulated with plane opaque surfaces characterized by specific optical properties. 


\subsubsection{Recent improvements of the DART code}

Since its first release, DART accuracy and potential were greatly improved at CESBIO (Centre d'Etudes Spatiales de la BIOsphère). For example, the robustness of its code and graphic user interface were significantly improved by the society Magellium Corp., in collaboration with CNES (French Space Center) and, CESBIO. Moreover, in order to reduce computational time, the paths of scattered rays always start from a predefined grid of points that sample cells and cell faces. In addition, the accuracy of R-T modeling between turbid cells was significantly improved: (1) scattering is now modeled with a "sector approach" (Gastellu-Etchegorry et al., 2004), which allows the code to run faster than the original "harmonic expansion approach" (Gastellu-Etchegorry et al., 1996). (2) At each DART iteration and for each turbid cell, DART stores $2 \times F \times N_{\text {sect }}$ "energetic points" (i.e. geometric coordinates and associated intercepted energies), where 2 stands for the upwards and downwards scattering hemispheres, $F$ is the number of input cell faces that intercept energy and $N_{\text {sect }}$ is the number of angular sectors (Martin, 2006). Within cell, multiple scattering is modeled with an analytical approach (Gastellu-Etchegorry et al., 1996) using the within cell first order scattered radiation that is intercepted within the cell before leaving it. DART also uses pre-computed volume optical properties of turbid cells such as

- $\mathrm{T}\left(\mathrm{j}, \Omega_{\mathrm{i}}\right)$ : transmittance of a unit path along $\left(\Omega_{\mathrm{i}}\right)$, for a unit volume density of leaf species $\mathrm{j}$. $\mathrm{T}\left(\mathrm{j}, \Omega_{\mathrm{i}}\right)=\exp \left[-G\left(\mathrm{j}, \Omega_{\mathrm{i}}\right)\right]$, where $G\left(j, \Omega_{\mathrm{i}}\right)$ is the mean projection of the leaf area unit in a plane perpendicular to direction $\Omega_{\mathrm{i}}$. Thus, the transmittance of a path $\Delta l$ along $\left(\Omega_{\mathrm{i}}\right)$ through a leaf cell of species $j$ and leaf volume density $u_{\mathrm{f}}(j)$ is $\mathrm{T}\left(\Delta \mathrm{l}, \Omega_{\mathrm{i}}\right)=\left[\mathrm{T}\left(\mathrm{j}, \Omega_{\mathrm{i}}\right)\right]^{u_{\mathrm{f}}(\mathrm{j}) \Delta \mathrm{l}}$. With an incident ray $\mathrm{W}_{\mathrm{in}}\left(0, \Omega_{\mathrm{i}}\right)$, a cell $\mathrm{j}$ transmits the energy $\mathrm{W}_{\text {trans }}\left(\Delta \mathrm{l}_{\mathrm{j}}, \Omega_{\mathrm{i}}\right)=\mathrm{T}\left(\Delta \mathrm{l}_{\mathrm{j}}, \Omega_{\mathrm{i}}\right) \mathrm{W}_{\text {in }}\left(0, \Omega_{\mathrm{i}}\right)$.

- $\mathrm{T}_{\mathrm{d}}\left(\mathrm{j}, \Omega_{\mathrm{i}}, \Omega_{\mathrm{v}}\right)$ : scattering transfer function, for a unit volume density of leaf species $j$. With an energy $\mathrm{W}_{\mathrm{int}}\left(f, \Omega_{\mathrm{i}}\right)$ intercepted along the path $\Delta l_{j}$, associated to an input cell face $f$, the energy scattered in an angular sector $\left(\Omega_{\mathrm{v}}, \Delta \Omega_{\mathrm{v}}\right)$ is
(Eq. (1)):

$$
\mathrm{W}_{\text {diff }}\left(f, \Omega_{\mathrm{v}}\right)=\mathrm{T}_{\mathrm{d}}\left(j, \Omega_{\mathrm{i}}, \Omega_{\mathrm{v}}\right) \mathrm{W}_{\text {int }}\left(f, \Omega_{\mathrm{i}}\right)
$$

For a radiation incident along $\left(\Omega_{\mathrm{i}}\right)$ in a turbid medium, both terms $T\left(j, \Omega_{\mathrm{i}}\right)$ and $\mathrm{T}_{\mathrm{d}}\left(\mathrm{j}, \Omega_{\mathrm{i}}, \Omega_{\mathrm{v}}\right)$ depend on $G\left(\mathrm{j}, \theta_{\mathrm{i}}\right)$ that is usually assumed to be azimuthally independent (Eq. (2)).

$G\left(j, \theta_{\mathrm{i}}\right)=\frac{1}{2 \pi} \int_{0}^{2 \pi} \mathrm{d} \Omega_{\mathrm{f}} \int_{0}^{1} g_{\mathrm{f}}\left(j, \Omega_{\mathrm{f}}\right)\left|\Omega_{\mathrm{i}} \Omega_{\mathrm{f}}\right| \mathrm{d} \mu_{\mathrm{f}} \lambda\left(\theta_{\mathrm{i}}\right)$

$g_{\mathrm{f}}\left(j, \Omega_{\mathrm{f}}\right)$ is the LAD of leaves oriented along direction $\Omega_{\mathrm{f}}$. DART uses two approaches for simulating clumping: (1) $G\left(j, \theta_{\mathrm{i}}\right)$ is weighted with a clumping index $\lambda\left(\theta_{\mathrm{i}}\right)$ (Martin, 2006), where $\theta_{\mathrm{i}}$ is the incident radiation zenith angle. This approached was used here to simulate BRDF with the 1D clumped scenes $\left(\lambda\left(\theta_{\mathrm{i}}\right)<1\right)$, (2) use of a structure parameter $P_{\mathrm{fc}}$ (i.e. the proportion of full cells in the vegetation canopy). This parameter was calibrated with in-situ transmittance measurements (see below) in order to build the maize 3D scenes.

\subsection{DART scenes construction}

BRDF are simulated for three types of scenes: 3D, 1D and 1D clumped (hereafter $1 \mathrm{D}^{\mathrm{cl}}$ ). DART 3D scenes consist of plant rows, using a trapezoidal volume. Two LAD are used for the simulations: spherical and plagiophile as they are the more commonly used to describe the maize canopy (Antunes et al., 2001; Guyot, 1997; Lopez-Lozano et al., 2007). Other structural characteristics were measured in the field for three growth stages of the maize stand (42, 57 and 70 days after sowing for the first, second and third growth stages, respectively): mean canopy height, distance between rows, width of the rows and destructive leaf area index (LAI $\left.{ }^{\text {dest }}\right)$. These parameters allow us to build 3D scenes taking into account the clumping at the row level. The clumping at the plant level is taken into account with the structural parameter $P_{\text {fc. It }}$ was assessed for each growth stage and each LAD through the fit of directional

Table 1 - Structural characteristics of the maize stand used to build the numerical scenes for three growth stages with the DART model and mean reflectances $(\rho)$ for maize leaves and the two types of soils in the red and near infrared (NIR) regions

\begin{tabular}{llll} 
Growth stage LAI $\left(\mathrm{m}^{2} \mathrm{~m}^{-2}\right)$ & \multicolumn{1}{c}{ 1st 0.95} & \multicolumn{1}{c}{ 2nd 3.2} & 3rd 5.0 \\
\hline Cells size $(x, y, z$ in $\mathrm{m})$ & $0.1,0.1,0.1$ & $0.1,0.1,0.1$ & $0.1,0.1,0.1$ \\
Leaf angle distribution & Spherical + plagiophile & Spherical + plagiophile & Spherical + plagiophile \\
Crown shape & Trapezoidal & $20 / 16$ & Trapezoidal \\
Percentage of full cells in the & $30 / 24$ & 1.45 & $20 / 16$ \\
$\quad$ canopy (spherical/plagiophile) & & 0.15 & 1.95 \\
Canopy mean height $(m)$ & 0.55 & 0.9 & 0.1 \\
Canopy bottom width $(m)$ & 0.05 & 0.8 & 0.75 \\
Canopy top width $(m)$ & 0.4 & 3.2 & 0.8 \\
Distance between rows $(m)$ & 0.8 & $04.8 / 52.0$ & 5 \\
Destructive leaf area index & 0.95 & $13.6 / 21.6$ & $04.8 / 52.0$ \\
$\rho$ Leaf (red/NIR) & $04.8 / 52.0$ & $46.1 / 50.7$ & $13.6 / 21.6$ \\
$\rho$ Loamy soil (red/NIR) & $13.6 / 21.6$ & & $46.1 / 50.7$ \\
$\rho$ Clay soil (red/NIR) & $46.1 / 50.7$ & & \\
\hline The parameters in italics have been measured in field. & &
\end{tabular}



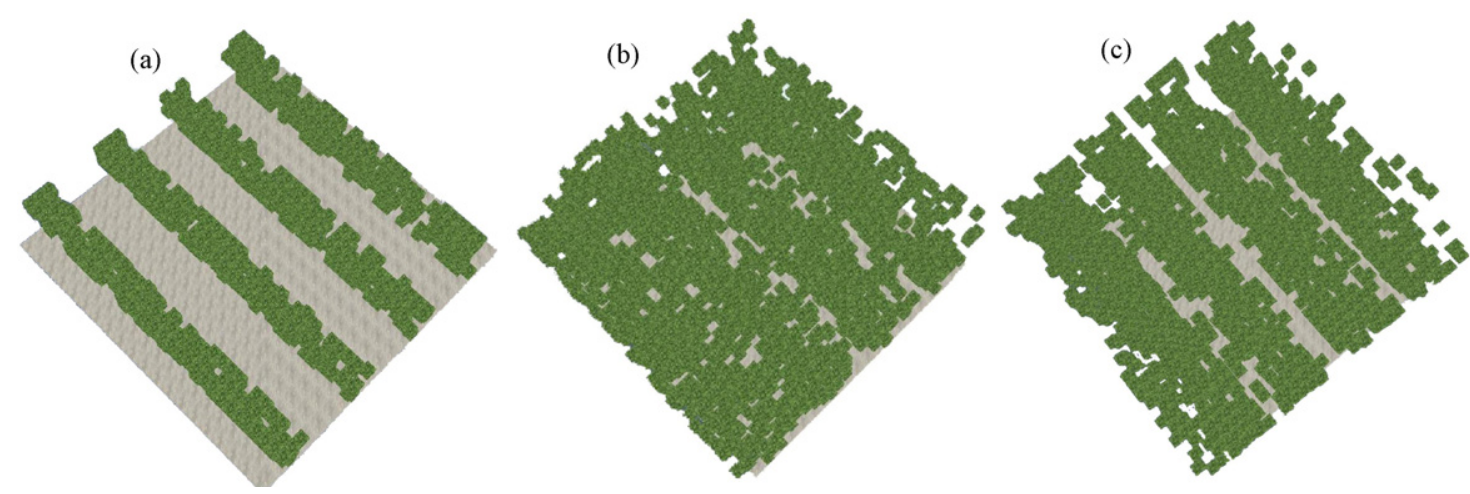

Fig. 1 - DART 3D scenes at three different growth stages (a) first growth stage, $\mathrm{LAI}^{\text {dest }}=0.95$, (b) second growth stage, $\mathrm{LAI}^{\text {dest }}=3.2$ and $(c)$ third growth stage, $\mathrm{LAI}^{\text {dest }}=5$. Maize rows are simulated with trapezoid shapes. From the radiative transfer point of view, the scene contains an infinite number of parallel maize rows.

DART gap fractions and directional gap fractions derived from hemispherical photographs analyzed with the CAN_EYE software (www.avignon.inra.fr/can_eye, Demarez et al., 2008).

Table 1 presents the main structural parameters used to build the maize 3D scenes and Fig. 1 shows the associated 3D scenes images.

DART 1D turbid scenes are built using only two parameters: the LAI measured in-situ and a spherical LAD, which implies $G(\theta)=0.5$ for any direction. 1D clumped turbid scenes differ from the 1D scenes by adding a clumping index either directional dependent $\lambda_{\mathrm{DART}}(\theta)$, or as directionally averaged $\lambda \lambda_{\mathrm{DART}}^{\text {mean }}$. The comparison of 1D BRDF simulations conducted with either $\lambda_{\text {DART }}(\theta)$ or $\lambda_{\text {DART }}^{\text {mean }}$ allows us to analyze the relevance of an angular dependence.

The modified Poisson law allows computing the $\lambda_{\operatorname{DART}}(\theta)$ for each growth stage from LAI measurements and DART gap fractions (Eq. (3)).

$\lambda_{\operatorname{DART}}(\theta)=\frac{-\ln \left(\mathrm{P}_{0}(\theta)^{\mathrm{DART}}\right) \cos (\theta)}{\mathrm{LAI}^{\text {dest }} G(\theta)}$

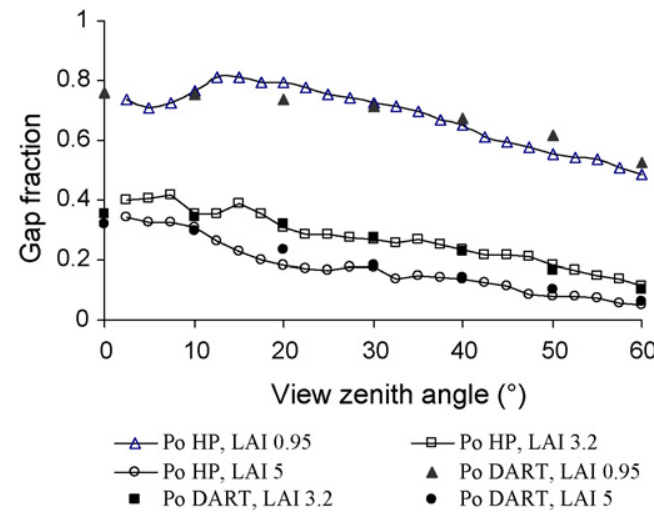

$\theta$ is the zenith angle of the incident direction. $P_{0}(\theta)^{\text {DART }}$ is averaged over the whole scene and over five azimuth angles $\varphi_{\mathrm{s}}$, starting from a direction perpendicular to the maize rows and ending with a direction parallel to the maize rows $\left(\varphi_{\mathrm{s}}=0^{\circ}, 22^{\circ}, 45^{\circ}, 68^{\circ}\right.$ and $\left.90^{\circ}\right)$. The isotropic clumping index $\lambda_{\mathrm{DART}}^{\text {mean }}$ is calculated by averaging $\lambda_{\mathrm{DART}}(\theta)$ over all considered view zenith angles, from $-60^{\circ}$ to $60^{\circ}$. As $\lambda_{\text {DART }}$ is determined from 3D scenes representing both plant arrangement and clumping inside each individual plant with a percentage of non empty cells, it mirrors these two scales of clumping.

\subsection{DART simulations}

TOC BRDF was simulated for the $3 \mathrm{D}, 1 \mathrm{D}$ and $1 \mathrm{D}^{\mathrm{cl}}$ (with $\lambda_{\operatorname{DART}}(\theta)$ or $\left.\lambda_{\mathrm{DART}}^{\text {mean }}\right)$ scenes, for each growth stage, for two spectral bands (red: $0.61-0.68 \mathrm{~nm}$ and NIR: $0.79-0.89 \mathrm{~nm}$ ), two types of soils (clay and loamy soils corresponding to bright and dark soils, respectively) and one leaf reflectance spectrum measured in the field. Clay soil spectrum originates from the ASTER database (USGS ASTER spectral

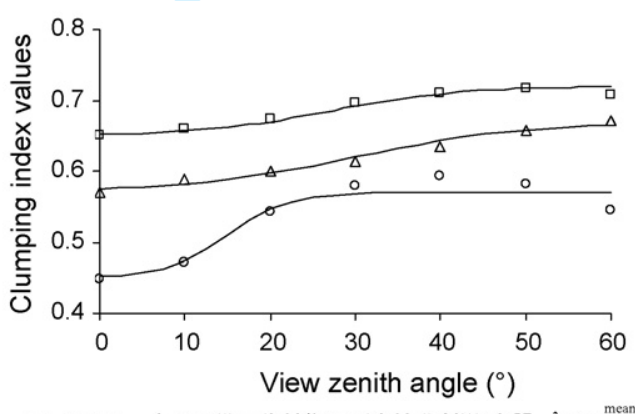

$\Delta \mathrm{LAI} 0.95, \lambda \operatorname{DART}(\theta)=(0.10 / 1+\exp (-0.10(\theta-30)))+0.57, \lambda{ }_{\text {DART }}{ }^{\text {mean }}=0.62$

$\square$ LAI 3.2, $\lambda$ DART $(\theta)=(0.07 / 1+\exp (-0.13(\theta-27)))+0.65, \lambda{ }_{\text {DART }}^{\text {mean }}=0.67$

○ LAI $5, \quad \lambda \operatorname{DART}(\theta)=(0.12 / 1+\exp (-0.28(\theta-15)))+0.45, \lambda_{\mathrm{DART}}{ }^{\text {mean }}=0.54$

Fig. 2 - (a) Evolution of the CAN_EYE gap fractions obtained from hemispherical photograpgy (HP) (open symbols) and simulated DART gap fractions with the zenith angle $\theta$ after an averaging over five azimuth angles for the three growth stage of the maize stand (black symbols), (b) evolution of the clumping index $\lambda_{\text {DART }}$ with $\theta$ for the three growth stages. Symbols represent the calculated $\lambda_{\text {DART }}$ (Eq. (3)) and lines represent the modeled sigmoids (Eq. (6)). Also shown are the sigmoid equations and mean clumping index $\lambda_{\mathrm{DART}}^{\text {mean }}$. 
Red
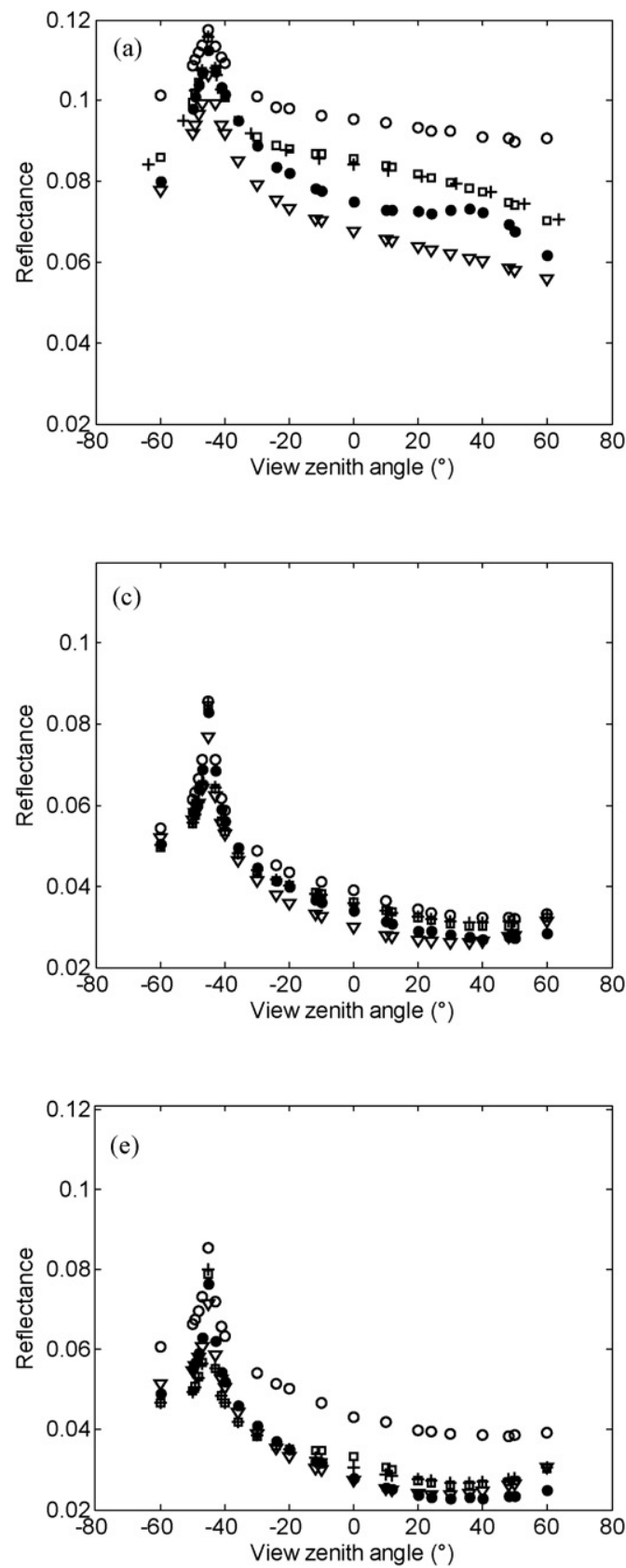

NIR
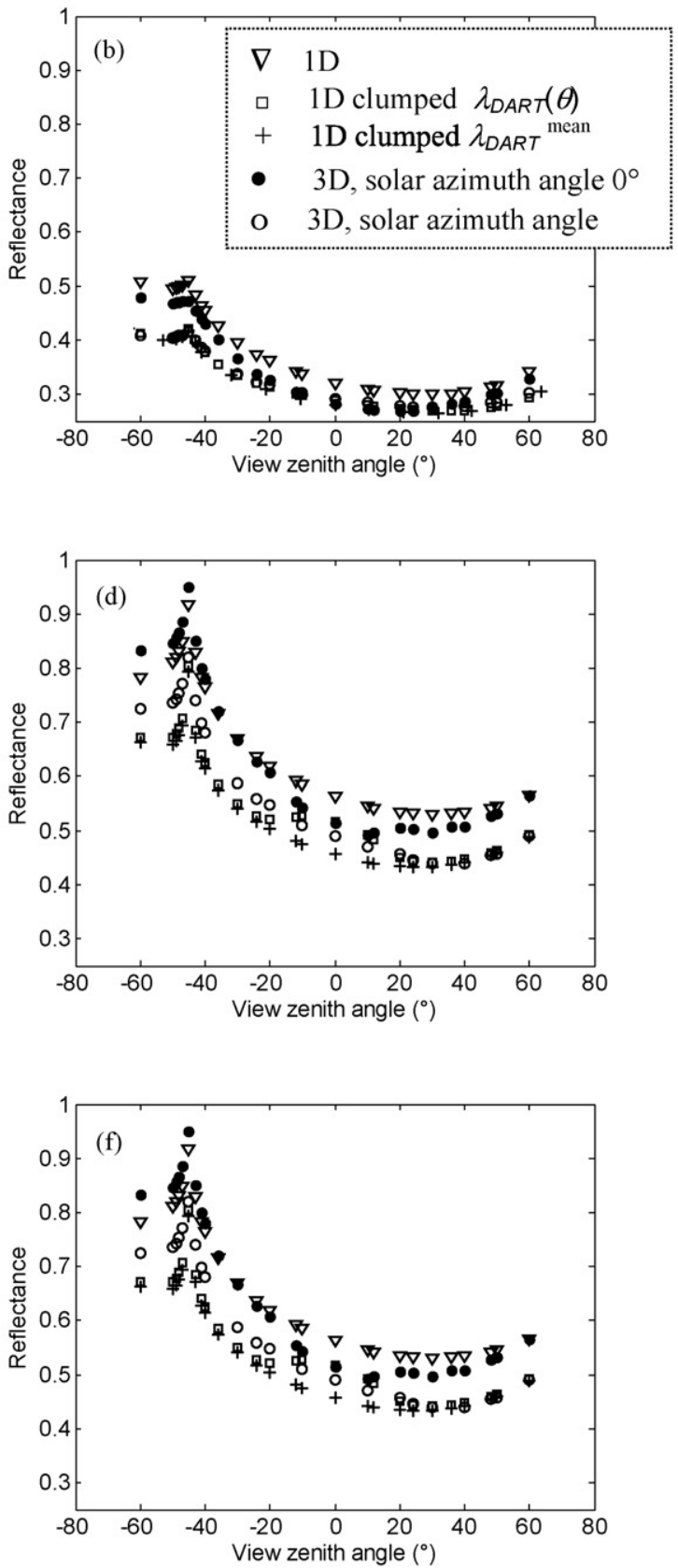

Fig. 3 - 3D, 1D and 1D clumped (using $\lambda_{\text {DART }}(\theta)$ and $\lambda_{D A R T}^{\text {mean }}$ BRDF simulated for the three growth stages (a and b: first stage $L A I^{\text {dest }}=0.95$; $b$ and d; second stage $\mathrm{LAI}^{\text {dest }}=3.2$; e and $\mathrm{f}$ : third stage $\mathrm{LAI} \mathrm{I}^{\text {dest }}=5$ ), a spherical leaf angle distribution, in the red and near infrared (NIR) spectral bands and the loamy soil The reflectance is observed in the principal plane with a solar zenith angle $\theta_{\mathrm{s}}$ of $45^{\circ}$.

library). Loamy soil and maize leaves spectra were measured in the field for a vertical view direction with a spectroradiometer (Field Spec pro FR, ASD). Table 1 shows the mean reflectance values $\rho$ for leaves and soils in the two spectral bands.

Simulations were computed in the principal and in the orthogonal planes, with a sun zenith angle $\theta_{\mathrm{s}}$ of $45^{\circ}$ and five azimuth angles $\varphi_{\mathrm{s}}$ described previously. Moreover, soil and leaf elements were assumed to be isotropic scatterers.
For each date and each sun configuration $\left(\theta_{\mathbf{s}}, \varphi_{\mathrm{s}}\right)$, mean relative difference (\%) between the 3D reflectances values and the $1 \mathrm{D}\left(\Delta^{3 \mathrm{D} / 1 \mathrm{D}}\right)$ (Eq. (4)) or $1 \mathrm{D}^{\mathrm{cl}}$ reflectances values $\left(\Delta^{3 \mathrm{D} / 1 \mathrm{D}^{\mathrm{cl}}}\right)$ (Eq. (5)) are calculated in the principal and orthogonal solar planes.

$\Delta^{3 \mathrm{D} / 1 \mathrm{D}}=\frac{1}{N} \sum_{1}^{N}\left[\frac{\left|\rho^{3 \mathrm{D}}-\rho^{1 \mathrm{D}}\right|}{\rho^{3 \mathrm{D}}}\right]$ 
$\Delta^{3 \mathrm{D} / 1 \mathrm{D}^{\mathrm{cl}}}=\frac{1}{N} \sum_{1}^{N}\left[\frac{\left|\rho^{3 \mathrm{D}}-\rho^{1 \mathrm{D}^{\mathrm{cl}}}\right|}{\rho^{3 \mathrm{D}}}\right]$

$\rho^{3 \mathrm{D}}, \rho^{1 \mathrm{D}}$ and $\rho^{1 \mathrm{D}^{\mathrm{cl}}}$ are reflectance values for $3 \mathrm{D}, 1 \mathrm{D}$ and $1 \mathrm{D}$ clumped representations of the maize canopy respectively, for each view zenith angle in the principal or orthogonal solar plane, and $N$ is the number of view zenith angles. The comparison of $\Delta^{3 \mathrm{D} / 1 \mathrm{D}}$ and $\Delta^{3 \mathrm{D} / 1 \mathrm{D}^{\mathrm{cl}}}$ provides a quantitative indication about the interest of using a clumping index in $\mathrm{R}-\mathrm{T}$ models that simulate reflectance values using turbid scenes.

\section{Results and discussion}

\subsection{DART gap fractions and associated clumping parameters}

Gap fractions $\left(P_{0}(\theta)^{\mathrm{DART}}\right)$ (Fig. 2a) decrease with the increase of view zenith angle $\theta$ for the three growth stages. $\lambda_{\text {DART }}(\theta)$ (Fig. 2b) globally increase with zenith angle accordingly to previous studies (Kucharik et al., 1999; Kuusk, 1995; Nouvellon et al., 2000), and this
Red
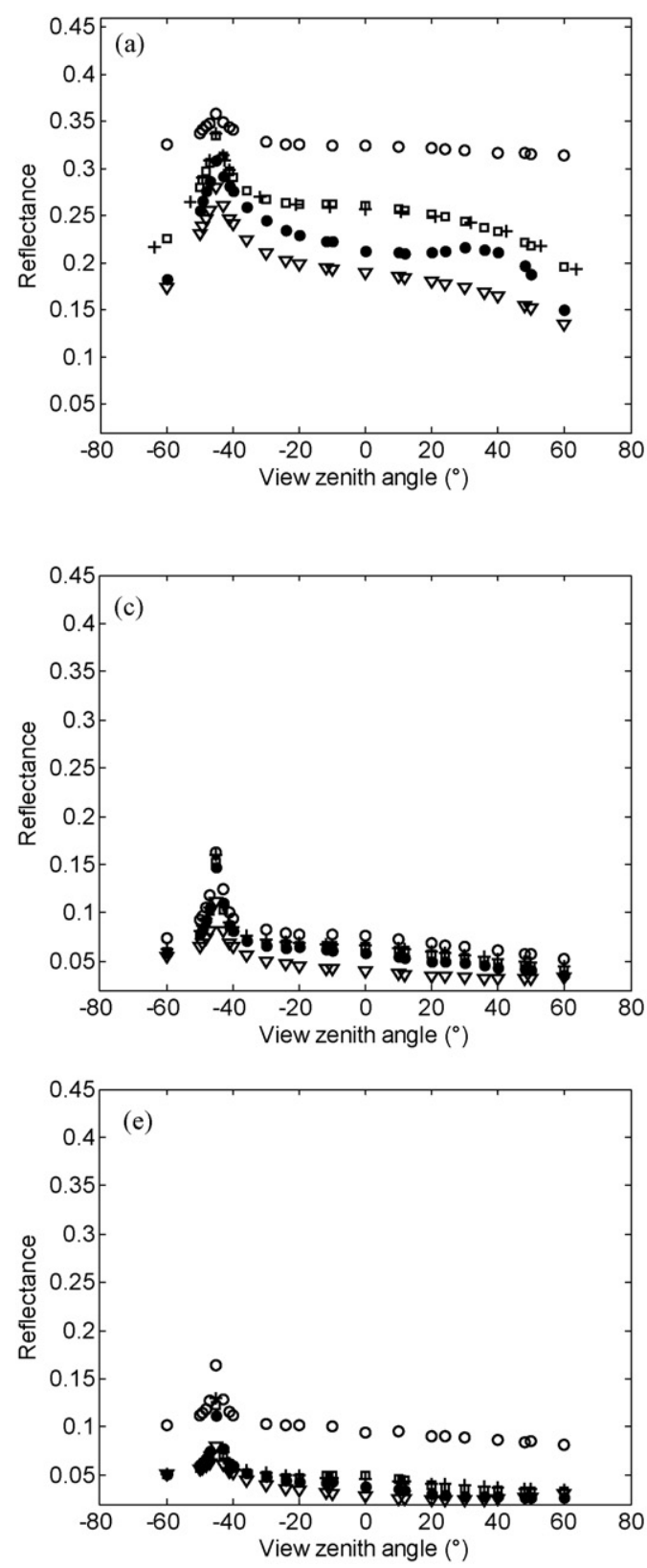

NIR
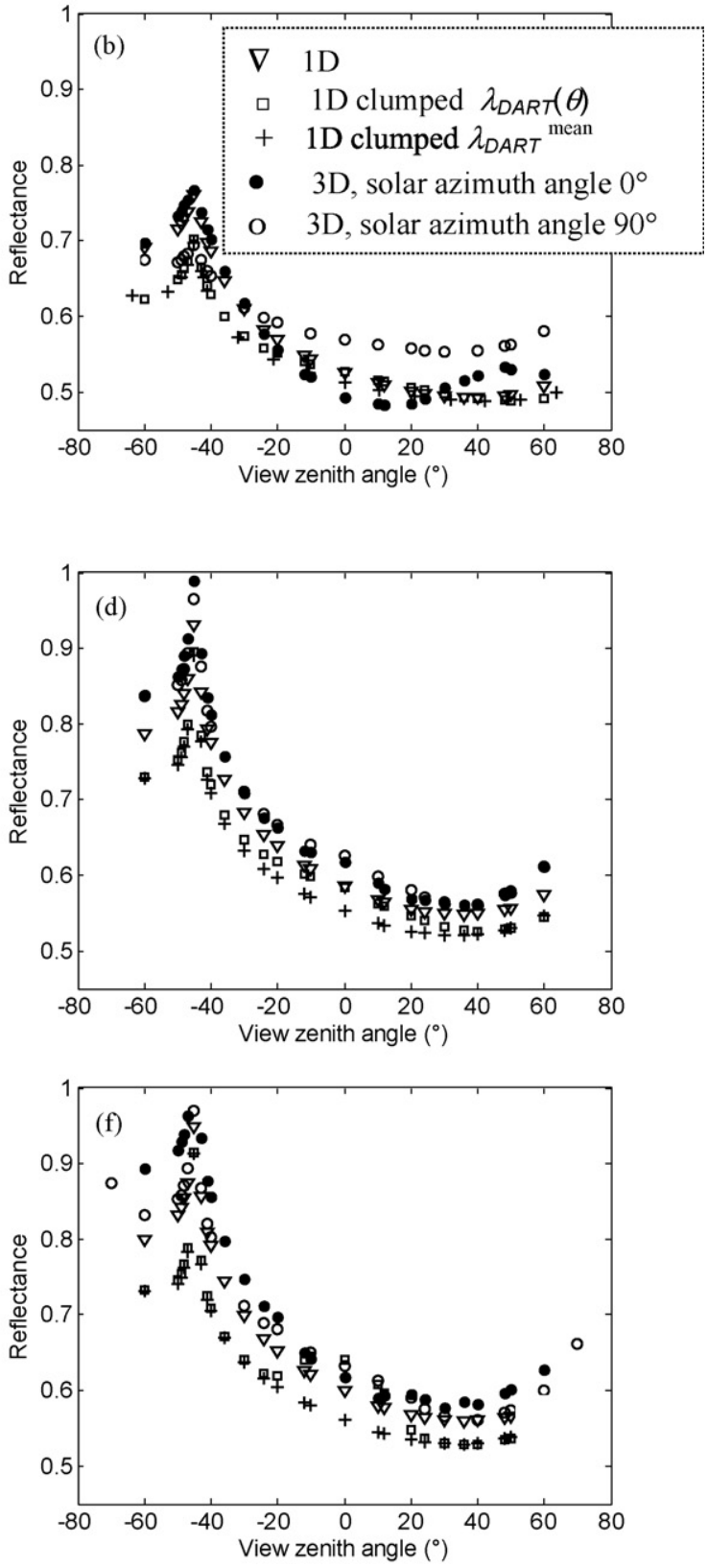

Fig. 4 - 3D, 1D, 1D clumped (using $\lambda_{\mathrm{DART}}(\theta)$ and $\lambda_{\mathrm{DART}}^{\text {mean }}$ ) BRDF simulated for the three growth stages (a and b: first stage $L A I^{\text {dest }}=0.95$; $b$ and d; second stage $L A I^{\text {dest }}=3.2$; e and f: third stage $L A I^{\text {dest }}=5$ ), a spherical leaf angle distribution, in the red and near infrared (NIR) spectral bands and the clay soil The reflectance is observed in the principal plane with a solar zenith angle $\theta_{\mathrm{s}}$ of $45^{\circ}$. 
functionality is well evaluated here with a sigmoid (Eq. (6)).

$\lambda_{\operatorname{DART}}(\theta)=\left(\frac{\lambda_{\text {diff }}}{1+\exp (-a(\theta-b))}+\lambda_{0}\right)$

where $\lambda_{0}$ is the clumping index in nadir direction, $\lambda_{\text {diff }}$ is the difference between the maximal and minimal values of $\lambda, a$ is the slope at the inflection point and $b$ is the inflection point.

Parameters $\lambda_{0}, \lambda_{\text {diff, }} a$ and $b$ were simultaneously adjusted using a minimization algorithm based on the simplex method (Nelder and Mead, 1965). Convergence was reached after a few iterations. Obtained sigmoid curves and equations are presented in Fig. 2.

Clumping index values are within the range $[0.45,0.72]$ and depend on plant growth stage and view direction (Fig. 2b) as already observed by several authors (Andrieu and Sinoquet, 1993; España et al., 1999; Kucharik et al., 1997; Lopez-Lozano et al., 2007). $\lambda_{\text {DART }}$ increases with view zenith angle. Its maximum value, or conversely minimum clumping effect, does not exceed the value of 0.72 . The departure from the Poisson model seems to be the largest at nadir as clumping

Red

(a)

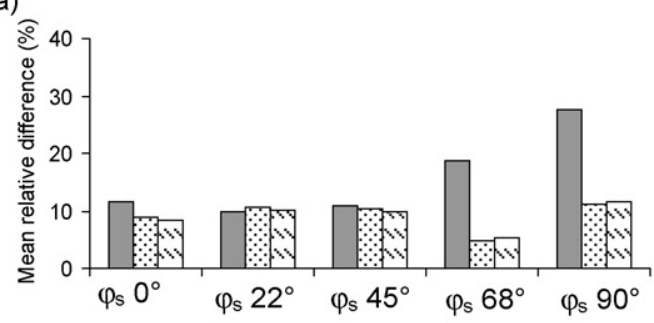

(c)

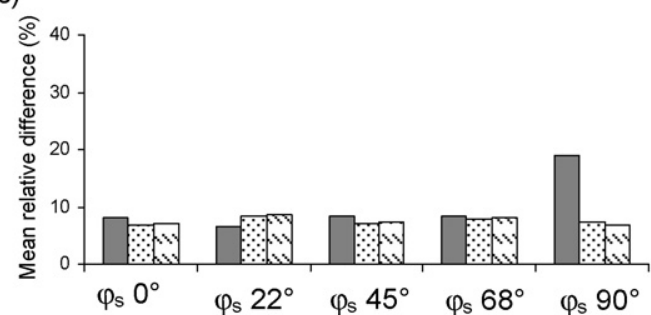

(e)

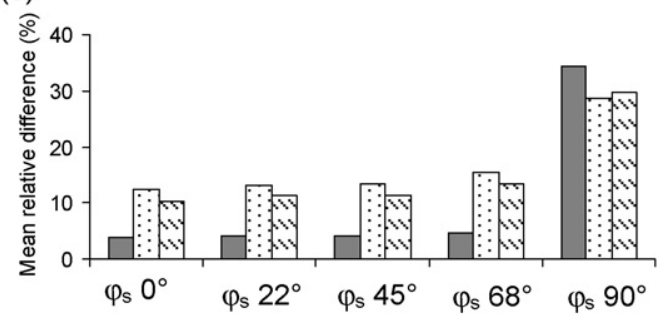

index values are the lowest for the three stages. It appears that the clumping does not necessarily decrease with LAI. Here, the second growth stage $(\mathrm{LAI}=3.2$ ) shows the lowest canopy clumpiness whereas clumping is strengthened at the last stage $(\mathrm{LAI}=5)$. Indeed, a concentration of leaves in the upper part of the canopy and an overlapping between plants of the same rows were observed in field and that, leads to an increase of clumpiness.

\subsection{Canopy BRDF simulations}

Figs. 3 and 4 shows the red and NIR BRDF curves simulated for the spherical LAD, for the three representations of the maize canopy (3D, 1D and 1D clumped) with the loamy (Fig. 3) and clay soil (Fig. 4), for the three stages of canopy growth, in the principal plane and two azimuth directions $\left(\varphi_{\mathrm{s}}=0^{\circ}\right.$ and $\left.90^{\circ}\right)$. For the 1D clumped simulations, two clumping indices are used: $\lambda_{\text {DART }}(\theta)$ and $\lambda_{\text {DART }}^{\text {mean }}$. Figs. 5 and 6 present the associated mean absolute relative differences between 3D and 1D BRDF $\left(\Delta^{3 \mathrm{D} / 1 \mathrm{D}}\right)$ and 3D and 1D clumped BRDF $\left(\Delta^{3 \mathrm{D} / 1 \mathrm{D}^{\mathrm{cl}}}\right.$ with $\lambda_{\mathrm{DART}}(\theta)$ or $\lambda_{\mathrm{DART}}^{\text {mean }}$ ) for a $\theta_{\mathrm{s}}$ of $45^{\circ}$, the five $\varphi_{\mathrm{s}}$ and the two types of soil. Fig. 7 presents the mean absolute relative differences $\Delta^{3 \mathrm{D} / 1 \mathrm{D}}$ and $\Delta^{3 \mathrm{D} / 1 \mathrm{D}^{\mathrm{cl}}}$ for the plagiophile LAD and the loamy soil.

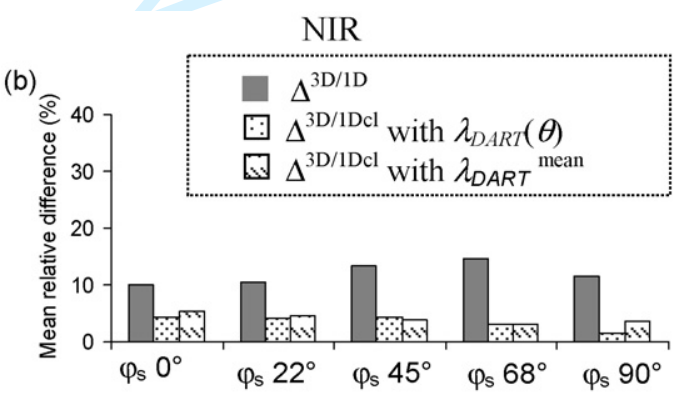

(d)
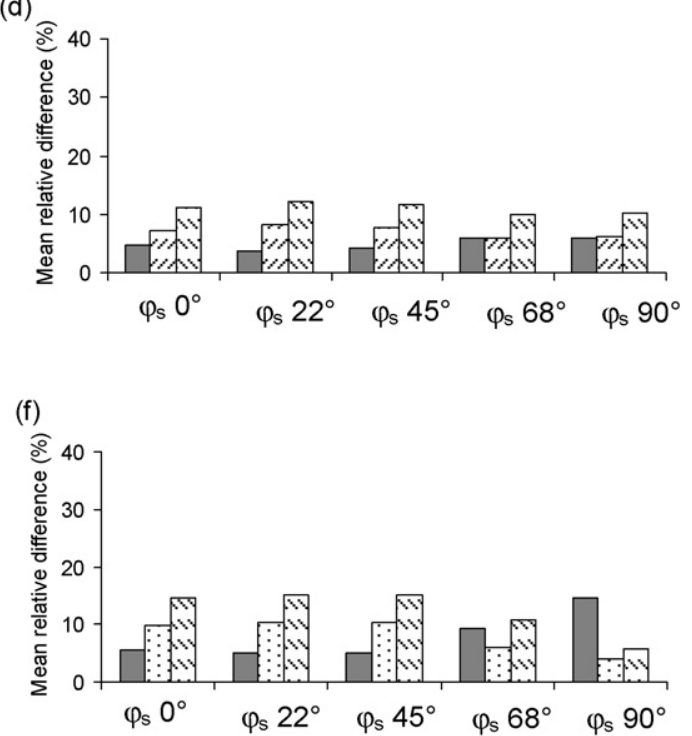

Fig. 5 - Mean relative differences between BRDF 3D and 1D $\left(\Delta^{3 \mathrm{D} / 1 \mathrm{D}}\right)$ or $1 \mathrm{D}$ clumped $\left(\Delta^{3 \mathrm{D} / 1 \mathrm{D}^{\mathrm{cl}}}\right.$, using $\lambda_{\mathrm{DART}}(\theta)$ and $\left.\lambda_{\mathrm{DART}}^{\text {mean }}\right)$ in the solar principal plane, in the red and near infrared (NIR) wavelengths for the three growth stages (a and b: first stage $\mathrm{LAI}^{\text {dest }}=0.95$, b and d; second stage $\mathrm{LAI}^{\text {dest }}=3.2$, e and $\mathrm{f}$ : third stage $\mathrm{LAI}^{\text {dest }}=5$ ), a spherical leaf angle distribution, the five solar azimuth angles, a solar zenith angle of $45^{\circ}$ and the loamy soil. 
Red

(a)

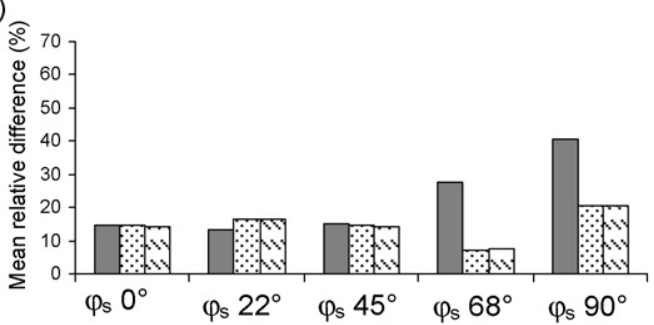

(c)

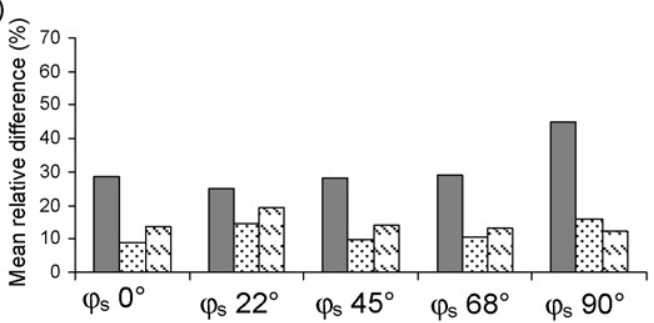

(e)

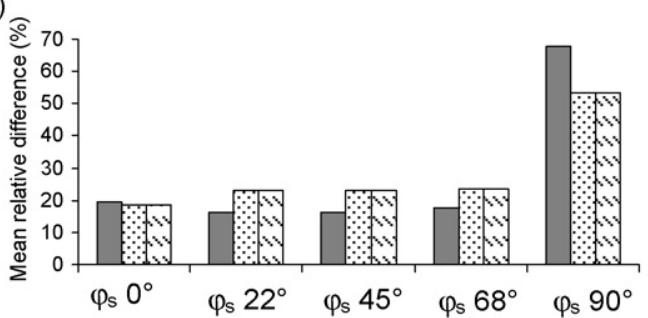

(b)

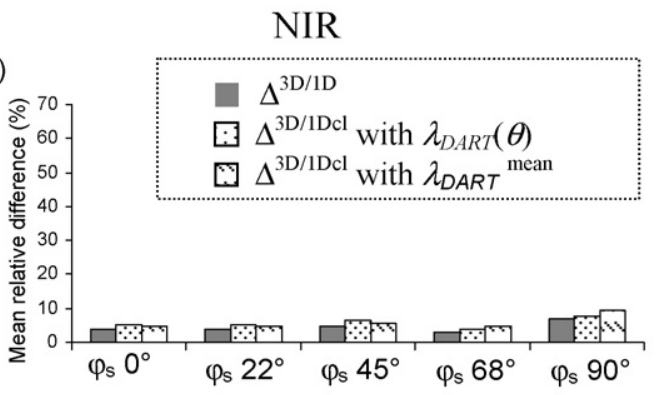

(d)

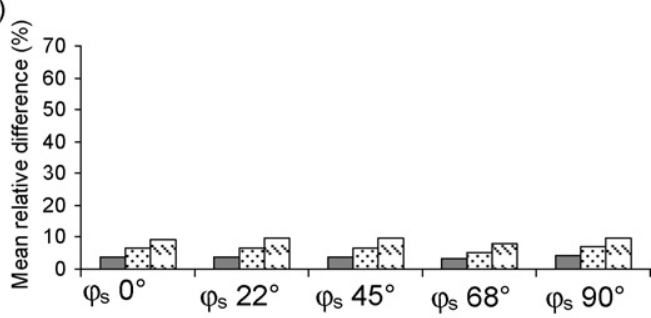

(f)

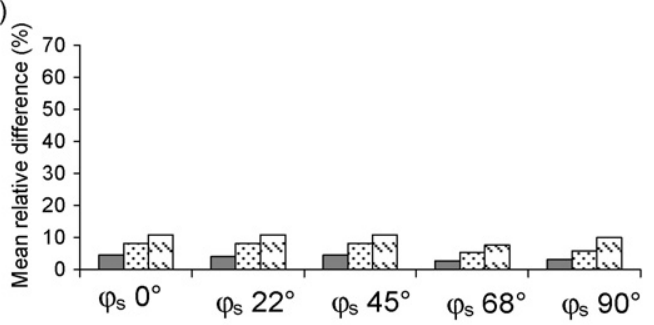

Fig. 6 - Mean relative differences between BRDF 3D and 1D $\left(\Delta^{3 \mathrm{D} / 1 \mathrm{D}}\right)$ or 1D clumped $\left(\Delta^{3 \mathrm{D} / 1 \mathrm{D}^{\mathrm{cl}}}\right.$, using $\lambda_{\mathrm{DART}}(\theta)$ and $\left.\lambda_{\mathrm{DART}}^{\text {mean }}\right)$ in the solar principal plane, in the red and near infrared (NIR) wavelengths for the three growth stages (a and b: first stage $\mathrm{LAI}^{\text {dest }}=0.95, \mathrm{~b}$ and d; second stage $\mathrm{LAI}^{\text {dest }}=3.2$, e and $\mathrm{f}$ : third stage $\mathrm{LAI}{ }^{\text {dest }}=5$ ), a spherical leaf angle distribution, the five solar azimuth angles, a solar zenith angle of $45^{\circ}$ and the clay soil.

As expected, an increase in LAI implies a global decrease of red reflectance and an increase of NIR reflectance (Figs. 3 and 4). Some differences between BRDF simulated with $\varphi_{\mathrm{s}}=0^{\circ}$ (illumination perpendicular to the row direction) and $90^{\circ}$ (illumination parallel to the row direction) are well visible. This can be explained by a difference of proportions of illuminated and shadowed soil. The red BRDF simulated for $\varphi_{\mathrm{s}}=90^{\circ}$ shows higher values with more than $50 \%$ of difference for the first growth stage. In the NIR wavelengths, differences are lower as shadows effects are smoothed due to the higher leaves reflectance. Similar patterns are observed with simulations carried out with the plagiophile LAD (not shown here).

\subsubsection{Comparisons between $3 D$ and $1 D$ BRDF curves}

As somewhat expected (Bégué et al., 1996; Goel and Thompson, 1984; Kuusk, 1994; Luquet et al., 1998; Major et al., 1992), the representation of the canopy with a turbid medium gives too much importance to the vegetation contribution on the total canopy reflectance.

In the red spectral domain and for the loamy soil, this leads to an underestimation of the BRDF in 1D due to the fact that leaf reflectance is smaller than soil reflectance (Fig. 3a, c and e).
Such discrepancy decreases progressively when LAI increases. It is particularly pronounced at the first growth stage where $\Delta^{3 \mathrm{D} / 1 \mathrm{D}}$ is between $10 \%$ and $28 \%$ depending on the illumination conditions (Fig. 5a). Moreover, this global underestimation increases with the proportion of illuminated soil. For example, for $\mathrm{LAI}=3.2$ and $5, \Delta^{3 \mathrm{D} / 1 \mathrm{D}}$ values vary between $4 \%$ and $8 \%$, excepted for the larger $\varphi_{\mathrm{s}}\left(90^{\circ}\right)$ where they reach $19 \%$ and $34 \%$ for the second and third growth stage respectively (Fig. 5c and e). Main results are globally similar for BRDF simulations carried out with the plagiophile LAD (Fig. 7a, c and e).

In the NIR wavelengths, where leaf reflectance is higher than soil reflectance, a global overestimation of the reflectance (Fig. 5b, $d$ and $\mathrm{f}$ ) is observed. Nevertheless, $\Delta^{3 \mathrm{D} / 1 \mathrm{D}}$ rarely reaches $10 \%$ except for high $\varphi_{\mathrm{s}}$. With a plagiophile LAD, $\Delta^{3 \mathrm{D} / 1 \mathrm{D}}$ values are globally higher, generally around 15\% (Fig. 7b, d and f).

With the clay soil, global underestimation of red 1D BRDF (Fig. 4a, c and e) still occurs and is even more pronounced: $\Delta^{3 \mathrm{D} /}$ ${ }^{1 D}$ values with a spherical LAD vary from $15 \%$ to $29 \%$ if $\varphi_{\mathrm{S}}=0^{\circ}$, depending on the growth stage (Fig. 6a, c and e). In the NIR, differences between 3D and 1D BRDF curves are low as leaves and soil reflectance values are quite similar, which suggests that in that case, 1D simulated scenes leads to accurate BRDF 
Red

(a)

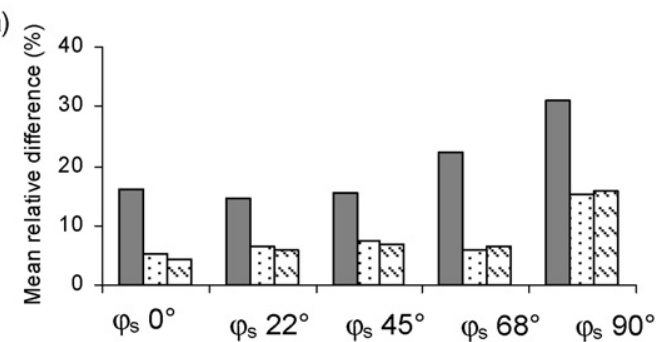

(c)

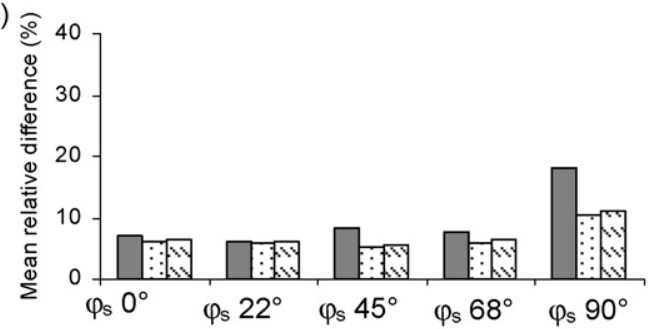

(e)

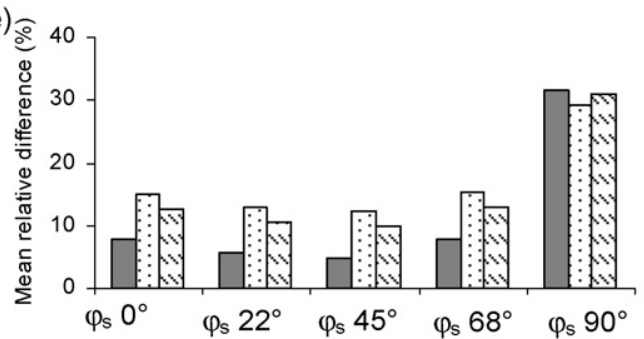

NIR

(b)

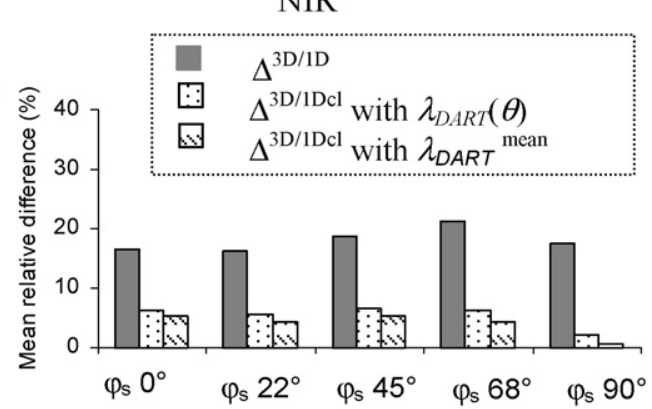

(d)

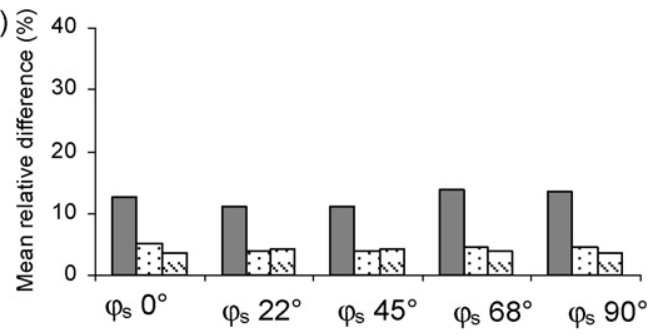

(f)

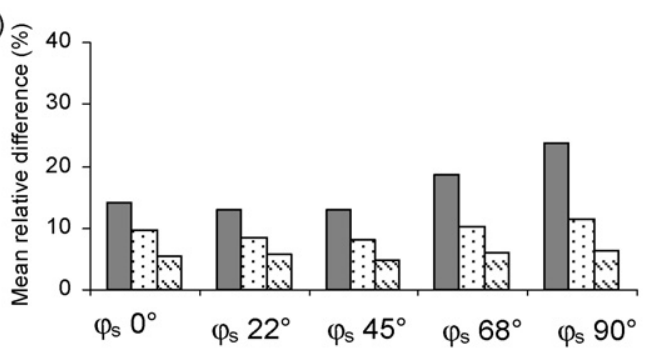

Fig. 7 - Mean relative differences between BRDF 3D and $1 \mathrm{D}\left(\Delta^{3 \mathrm{D} / 1 \mathrm{D}}\right)$ or $1 \mathrm{D}$ clumped $\left(\Delta^{3 \mathrm{D} / 1 \mathrm{D}^{\mathrm{cl}}}\right.$ using $\lambda_{\mathrm{DART}}(\theta)$ and $\left.\lambda_{\mathrm{DART}}^{\text {mean }}\right)$ in the solar principal plane, in the red and near infrared (NIR) wavelengths for the three growth stages (a and b: first stage $\mathrm{LAI}^{\mathrm{dest}}=0.95$, b and d; second stage $\mathrm{LAI}{ }^{\text {dest }}=3.2$, e and f: third stage $\mathrm{LAI}^{\text {dest }}=5$ ), a plagiophile leaf angle distribution, the five solar azimuth angles, a solar zenith angle of $45^{\circ}$ and the loamy soil.

simulations. Same tendencies are also observed with the plagiophile LAD (not shown here).

For all cases, smaller differences usually occur in or near the hot spot direction because the proportion of viewed shadows is minimum in this geometry. For hot spot situations, present results confirm major discrepancies existing between 1D and 3D scenes for high LAI values and enhanced spectral contrasts between vegetation and soil.

The main results obtained in the orthogonal solar plane (not shown here) for the two $\theta_{\mathrm{s}}$ are comparable and the percentages of differences between simulated $3 \mathrm{D}$ and $1 \mathrm{D}$ reflectance values are very similar.

3.2.2. Comparisons between $3 D$ and $1 D$ clumped BRDF curves Compared to 1D scenes, 1D scenes with clumping simulated using $\lambda_{\operatorname{DART}}(\theta)$ give larger transmittance values, which increases soil contribution on total canopy reflectance.

In the red region, the relative difference $\Delta^{3 \mathrm{D} / 1 \mathrm{D}^{\mathrm{cl}}}$ is then globally lower than $\Delta^{3 \mathrm{D} / 1 \mathrm{D}}$ for the two first growth stages, particularly for large $\varphi_{\mathrm{s}}$ (Fig. 3a and c and Fig. 4a and c). This improvement is enhanced with the high reflective soil (Fig. 4) and with low $\theta_{\mathrm{s}}$.

In the NIR, no improvements are observed with the clay soil, i.e. when the spectral contrast between leaves and soil is low, and results deteriorate as $\Delta^{3 \mathrm{D} / 1 \mathrm{D}^{\mathrm{cl}}}$ values are globally beyond the $\Delta^{3 \mathrm{D} / 1 \mathrm{D}}$ values, except for large $\varphi_{\mathrm{S}}\left(90^{\circ}\right)$. With the loamy soil, i.e. when the when the spectral contrast between leaves and soil is high, $\Delta^{3 \mathrm{D} / 1 \mathrm{D}^{\mathrm{cl}}}$ is globally lower than $\Delta^{3 \mathrm{D} / 1 \mathrm{D}}$ for the first growth stage, whatever the LAD. For the other growth stages, as already seen above, 1D BRDF simulations are relevant with a spherical LAD and $\Delta^{3 \mathrm{D} / 1 \mathrm{D}^{\mathrm{cl}}}$ values are globally higher than $\Delta^{3 \mathrm{D} / 1 \mathrm{D}}$ (Fig. 5d and f). For example, with LAI $=3.2$ and $\varphi_{\mathrm{s}}=22^{\circ}, \Delta^{3 \mathrm{D} / 1 \mathrm{D}}=4 \%$ although $\Delta^{3 \mathrm{D} / 1 \mathrm{D}^{\mathrm{cl}}}$ reaches $8 \%$. On the contrary, with a plagiophile LAD, using $1 \mathrm{D}$ clumped scenes allow a general improvement of the BRDF simulation in the NIR for these two last growth stages. Indeed, the mean relative difference with 3D BRDF globally decrease from around $15 \%$ to $5 \%$ with $\lambda_{\text {DART }}^{\text {mean }}$ (Fig. $7 d$ and f). Here again, major results are quite similar in the solar orthogonal plane (not shown here).

It is interesting to note that BRDF curves simulated in the NIR with $1 \mathrm{D}^{\mathrm{cl}}$ scenes with $\lambda_{\mathrm{DART}}(\theta)$ for large LAI show no realistic features near the nadir direction since a sudden increase of the reflectance that does not occur on the 3D BRDF curve (Fig. 3d and f and Fig. 4f) can be observed. This result strongly underlines the errors related to a simplified description of the vegetation architecture with 1D scenes (1) by assuming that leaf contribution is the same at all canopy levels and (2) by increasing artificially the proportion of radiation 
Table 2 - Summary of the improvements observed when simulating BRDF using a clumping index $\lambda$ for the several cases studied: in the red and near infrared (NIR) wavelengths, for the three growth stages $(\mathrm{LAI}=0.95,3.2$ and 5$)$ and the two leaf angle distributions (LAD, spherical and plagiophile)

Interest of using $\lambda$ for simulating $1 \mathrm{D}$ BRDF Red wavelengths

NIR wavelengths

\begin{tabular}{|c|c|c|c|c|c|c|c|}
\hline & & & & & & & \\
\hline & & LAI 0.95 & LAI 3.2 & LAI 5 & LAI 0.95 & LAI 3.2 & LAI 5 \\
\hline \multirow[t]{2}{*}{ High spectral contrast between soil and leaves } & Spherical LAD & Yes & Yes & $\mathrm{x}$ & Yes & $\mathrm{x}$ & $\mathrm{x}$ \\
\hline & Plagiophile LAD & Yes & Yes & Yes & Yes & Yes & Yes \\
\hline \multirow[t]{2}{*}{ Low spectral contrast between soil and leaves } & Spherical LAD & Yes & Yes & $\mathrm{x}$ & $\mathrm{X}$ & $\mathrm{x}$ & $\mathrm{x}$ \\
\hline & Plagiophile LAD & Yes & Yes & $\mathrm{X}$ & $\mathrm{X}$ & $\mathrm{x}$ & $\mathrm{x}$ \\
\hline
\end{tabular}

Yes: an improvement was observed when using $\lambda$ to simulated canopy BRDF; X: no improvement observed.

reaching the lower layers of the canopy with the use of a clumping index. Therefore, using $\lambda$ in the NIR wavelengths with high LAI does not improve BRDF simulations and leads also to an unrealistic simulated BRDF curve near the nadir direction by strongly overestimating leaves scattering.

Finally, it has been shown that when an improvement is observed using $\lambda_{\mathrm{DART}}(\theta)$, comparable results are generally obtained using $\lambda_{\mathrm{DART}}^{\text {mean }}$ (Figs. 5-7), suggesting that there is no strong recommendation to take into account the zenith angular variation of the clumping index to improve BRDF simulations.

Main results are summarized in Table 2 for all the cases studied. They show that using $\lambda$ to simulate the BRDF of the maize canopy can globally help to better simulate the BRDF, especially when the spectral contrast between leaves and soil is high. Nevertheless, in some cases, the results can be even worse than those obtained with a 1D turbid medium, especially in the NIR region and for high LAI. The potential improvements are thus strongly dependent on the LAI, the spectral contrast between soil and leaves reflectance values and the considered wavelengths.

\section{Concluding remarks}

The major aim of this study is to determine to which extent the use of a clumping index $\lambda$ within 1D turbid reflectance models could improve their BRDF simulations in the case of a heterogeneous row crop. Three growth stages (LAI $=0.95$, $\mathrm{LAI}=3.2$ and $\mathrm{LAI}=5$ ) are studied and for each of them, different numerical scenes corresponding to different levels of heterogeneity are simulated: 3D or 1D scenes with randomly distributed (clumping index $\lambda=1$ ) or clumped $(\lambda<1)$ leaves. 3D simulations processed with the DART model (GastelluEtchegorry et al., 1996, 2004) are chosen are references for the evaluation of $1 \mathrm{D}$ simulations.

In most of the cases, it appears that it is not worth taking into account the zenith angular variation of the clumping index $\lambda$ since the use of a mean clumping index gives similar results. This simplifies the use of the clumping index in 1D R-T models. It has also been demonstrated that the use of $\lambda$ globally improves 1D BRDF simulations in the red wavelengths for all growth stages with the highly reflective clay soil. If the contrast between soil and leaves is lower (loamy soil in our case), the use of a clumping index seems only relevant during the two first growth stages. In the high scattering NIR wavelengths, using a clumping index is only interesting in a few cases if the contrast between soil and leaves is high (loamy soil in our case). With the clay soil, it appears that 1D simulations are in all cases more relevant than $1 \mathrm{D}$ clumped simulations.

The advantages of using a clumping index in 1D R-T models are highlighted in this work, but its limits are also pointed out. Poor results, found particularly in the high scattering NIR region and for high LAI, are due to an overestimation of leaf density in the lower canopy layers with the 1D representation of the canopy, and this effect is increased with the introduction of a clumping index.

Recent development of methods that allow a mapping of clumping indexes from remote sensing datasets (Chen et al., 2003, 2005; Lacaze et al., 2002) could help to improve light interactions and BRDF simulations in heterogeneous canopies with turbid radiative transfer models, especially in the visible wavelengths. To which extent this could lead to better LAI estimations by inversion of reflectance remote sensing data is still matter of concern and investigation.

\section{Acknowledgements}

The authors would like to thank Mr. Gay from the Ecole Supérieure d'Agriculture de Purpan (ESAP, France) for allowing us to make measurements in the maize field. We also thank Dr. Valérie Le Dantec and Dr. Anne Chaponnière for their help in that work.

\section{R E F E R E N C E S}

Andrieu, B., Sinoquet, H., 1993. Evaluation of structure description requirements for predicting gap fraction of vegetation canopies. Agric. Forest Meteorol. 65, 207-227.

Antunes, M.A.H., Walter-Shea, E.A., Mesarch, M.A., 2001. Test of an extended mathematical approach to calculate maize leaf area index and leaf angle distribution. Agric. Forest Meteorol. 108, 45-53.

Bacour, C., Baret, F., Béal, D., Weiss, M., Pavageau, K., 2006. Neural network estimation of LAI, fAPAR, fCover and $\mathrm{LAI} \times \mathrm{C}_{\mathrm{ab}}$, from top of canopy MERIS reflectance data: principles and validation. Remote Sens. Environ. 105 (4), 313-325.

Baldocchi, D., Collineau, S., 1994. The physical nature of solar radiation in heterogeneous canopies: spatial and temporal attributes. In: Caldwell, M.M., Pearcy, M.W. (Eds.), Exploitation of Environmental Heterogeneity by Plants: Ecophysiological Processes Above- and Belowground. Academic Press, San Diego, CA, pp. 21-71. 
Baret, F., Hagolle, O., Geiger, B., Bicheron, P., Miras, B., Huc, M., Berthelot, B., Niño, F., Weiss, M., Samain, O., Roujean, J.-L., Leroy, M., 2007. LAI, fAPAR and fCover CYCLOPES global products derived from VEGETATION. Part 1: principles of the algorithm. Remote Sens. Environ. 110, 275-286.

Bégué, A., Prince, S.D., Hanan, N.P., Roujean, J.-L., 1996. Shortwave radiation budget of Sahelian vegetation. 2. Radiative transfer model. Agric. Forest Meteorol. 79, 97-112.

Bicheron, P., Leroy, M., 1999. A method of biophysical parameter retrieval at global scale by inversion of a vegetation reflectance model. Remote Sens. Environ. 67, 251-266.

Chen, J.M., Black, T.A., 1992. Defining leaf area index for non flat leaves. Plant Cell Environ. 15, 421-429.

Chen, J.M., Liu, J., Leblanc, S.G., Lacaze, R., Roujean, J.-L., 2003. Multi-angular optical remote sensing for assessing vegetation structure and carbon absorption. Remote Sens. Environ. 84, 516-525.

Chen, J.M., Menges, C.H., Leblanc, S.G., 2005. Global mapping of foliage clumping index using multi-angular satellite data. Remote Sens. Environ. 97, 447-457.

Demarez, V., 1997. Modélisation du transfert radiatif et télédétection hyperspectrale pour le suivi temporel de la teneur en chlorophylle d'une forêt tempérée, PhD Thesis, Université Paul Sabatier, Toulouse, France.

Demarez, V., Gastellu-Etchegorry, J.-P., Mordelet, P., Tosca, C., Marty, G., Guillevic, P., 2000. Modeling of the radiation regime and photosynthesis of a finite canopy using the DART model. Influence of canopy architecture assumptions and border effects. Agronomie 20, 259-270.

Demarez, V., Duthoit, S., Baret, F., Weiss, M., Dedieu, G., 2008. Estimation of leaf area and clumping indexes of crops with hemispherical photographs. Agric. Forest Meteorol. 148 (4), 644-655.

España, M., Baret, F., Ariès, F., Andrieu, B., Chelle, M., 1999. Radiative transfer sensitivity to the accuracy of canopy structure description. The case of a maize canopy. Agronomie 19, 241-254.

Gascon, F., 2001. Modélisation physique d'images de télédétection optique. Thèse, Université Paul Sabatier, Toulouse, France, 169 p.

Gastellu-Etchegorry, J.-P., Demarez, V., Pinel, V., Zagolski, F., 1996. Modeling radiative transfer in heterogeneous 3-D vegetation canopies. Remote Sens. Environ. 58, 131-156.

Gastellu-Etchegorry, J.-P., Guillevic, P., Zagolski, F., Demarez, V., Trichon, V., Deering, D., Leroy, M., 1999. Modeling BRF and radiation regime of tropical and boreal forests. Part I: BRF. Remote Sens. Environ. 68, 281-316.

Gastellu-Etchegorry, J.P., Gascon, F., Estève, P., 2003. An interpolation procedure for generalizing a look-up table inversion method. Remote Sens. Environ. 87, 55-71.

Gastellu-Etchegorry, J.-P., Martin, E., Gascon, F., 2004. DART: a 3D model for simulating satellite images and studying surface radiation budget. Int. J. Remote Sens. 25 (1), 73-96.

Goel, N.S., Strebel, D.E., 1983. Inversion of vegetation canopy reflectance models for estimating agronomic variables. I. Problems definition and initial results using the Suits model. Remote Sens. Environ. 13, 487-507.

Goel, N.S., Thompson, R.L., 1984. Inversion of vegetation canopy reflectance models for estimating agronomic variables. IV. Total inversion of the SAIL model. Remote Sens. Environ. 15, 237-253.

Guillevic, P., Gastellu-Etchegorry, J.-P., 1999. Modelling BRF and radiation regime of boreal and tropical forests: II. PAR regime. Remote Sens. Environ. 68, 317-340.

Guyot, G., 1997. Climatologie de l'environnement: de la plante aux écosystèmes. Masson ed.

Hu, J., Su, Y., Tan, B., Huang, D., Yang, W., Schull, M., Bull, M.A., Martonchik, J.V., Diner, D.J., Knyazikhin, Y., Myneni, R.B., 2007. Analysis of the MSIR LAI/FPAR product for spatial and temporal coverage, accuracy and consistency. Remote Sens. Environ. 107, 334-347.

Jacquemoud, S., Bacour, C., Poilvé, H., Frangi, J.-P., 2000. Comparison of four radiative transfer models to simulate plant canopies reflectance: direct and inverse mode. Remote Sens. Environ. 74, 471-481.

Jonckheere, I., Fleck, S., Nackaerts, K., Muys, B., Coppin, P., Weiss, M., Baret, F., 2004. Review of methods for in situ leaf area index determination. Part I. Theories, sensors and hemispherical photography. Agric. Forest Meteorol. 121, 1935.

Kallel, A., Le Hégarat-Mascle, S., Ottlé, C., Hubert-Moy, L., 2007. Determination of vegetation cover fraction by inversion of a four-parameter model based on isoline parametrization. Remote Sens. Environ. 111 (4), 553-566.

Kimes, D., Gastellu-Etchegorry, J.P., Estève, P., 2002. Recovery of forest canopy characteristics through inversion of a complex 3D model. Remote Sens. Environ. 79, 320-328.

Knyazikhin, Y., Martonchik, J.V., Myneni, R.B., Diner, D.J., Running, S.W., 1998. Synergistic algorithm for estimating vegetation canopy leaf area index and fraction of absorbed photosynthetically active radiation from MODIS and MISR data. J. Geophys. Res. 103 (D24), 32257-32276.

Kucharik, C.J., Norman, J.M., Murdock, L.M., Gower, S.T., 1997. Characterizing canopy non randomness with a multiband vegetation imager, (MVI). J. Geophys. Res. 102 (D24), 2945529473.

Kucharik, C.J., Norman, J.M., Gower, S.T., 1999. Characterization of radiation regimes in non-random forest canopies: theory, measurements, and simplified modeling approach. Tree Physiol. 19, 695-706.

Kuusk, A., 1994. A multispectral canopy reflectance model. Remote Sens. Environ. 50, 75-82.

Kuusk, A., 1995. A Markov chain model of canopy reflectance. Agric. Forest Meteorol. 76, 221-236.

Lacaze, R., Chen, J.M., Roujean, J.-L., Leblanc, S., 2002. Retrieval of vegetation clumping index using hot spot signatures measured by POLDER instrument. Remote Sens. Environ. 79, 84-95.

Lauvernet, C., Baret, F., Hascoët, L., Buis, L., Le Dimet, F.-X., 2008. Multitemporal-patch ensemble inversion of coupled surface-atmosphere radiative transfer models for land surface characterization. Remote Sens. Environ. 112 (3), 851-861.

Lemeur, R., Blad, B.L., 1974. A critical review of light models for estimating the shortwave radiation regime of plant canopies. Agric. Forest Meteorol. 14 255-286x.

Lopez-Lozano, R., Baret, F., Chelle, M., Rochdi, N., España, M., 2007. Sensitivity of gap fraction to maize architectural characteristics based on 4D model simulations. Agric. Forest Meteorol. 143, 217-229.

Luquet, B., Begué, A., Dauzat, J., Nouvellon, Y., Rey, H., 1998. Effect of the vegetation clumping on the BRDF of a semi-arid grassland; comparison of the SAIL model and ray tracing method applied to a 3D computerized vegetation. IGARSS'98, Seattle, WA, July, 6-10, 1998.

Major, D.J., Schaalje, G.B., Wiegand, C., Blad, B.L., 1992. Accuracy and sensitivity analyses of SAIL model-predicted reflectance of maize. Remote Sens. Environ. 41, 61-70.

Malenovský, Z., Martin, E., Homolova, L., Gastellu-Etchegorry, J.P., Zurita-Milla, R., Schaepman, M.E., Pokorny, R., Clevers, J.G.P.W., Cudlin, P., 2008. Influence of woody elements of a Norway Spruce canopy on nadir reflectance simulated by the DART model at very high spatial resolution. Remote Sens. Environ. 112, 1-18.

Martin E., 2006. DART: Modèle 3-D multispectral et inversion d'images optique de satellite-Applications aux couverts forestiers. Thèse, Université Paul Sabatier, Toulouse, France, $208 \mathrm{p}$. 
Monsi, M., Saeki, T., 1953. Über den Lichtfaktor in den Pflanzengesellschaften und seine Bedeutung für die Stoffproduktion. Jpn. J. Bot. 14, 22-52.

Morisette, J., Baret, F., Privette, J.L., Myneni, R.B., Nickeson, J., Garrigues, S., Shabanov, N., Weiss, M., Fernandes, R., Leblanc, S.G., Kalacska, M., Sanchez-Azofeifa, G.A., Chubey, M., Rivard, B., Stenberg, P., Rautiainen, M., Voipio, P., Manninen, T., Pilant, D., Lewis, T., Iiames, J., Colombo, R., Meroni, M., Busetto, L., Cohen, W.B., Turner, D.P., Warner, D., Petersen, G.W., Seufert, G., Cook, R., 2006. Validation of global moderate resolution LAI Products: a framework proposed within the CEOS Land Product Validation subgroup. IEEE Trans. Geosci. Remote Sens. 44 (7), 1804-1817.

Myneni, R.B., Nemani, R.R., Running, S.W., 1997. Estimation of global leaf are index and absorbed Par using radiative transfer models. IEEE Trans. Geosci. Remote Sens. 35 (6), 1380-1393.

Nelder, J.A., Mead, R., 1965. A simplex for function minimization. Compu. J. 7, 308-313.

Nilson, T., 1971. Inversion of the frequency of gaps in plant stands. Agric. Forest Meteorol. 8, 25-38.

Nouvellon, Y., Bégué, A., Moran, M.S., Lo Seen, D., Rambal, S., Luquet, D., Chehbouni, A., Inoue, Y., 2000. PAR extinction in shortgrass ecosystems: effects of clumping, sky conditions and soil albedo. Agric. Forest Meteorol. 105, 21-41.

Pinel, V., Gastellu-Etchegorry, J.P., 1998. Sensitivity of texture of high resolution images of forest to biophysical and acquisition parameters. Remote Sens. Environ. 65, 61-85.

Pinty, B., 1990. A physical model of the bidirectional reflectance of vegetation canopies. 2. Inversion and validation. J. Geophys. Res. 95, 11767-11775.

Pinty, B., Gobron, N., Widlowski, J.L., Gerstl, S.A.W., Vertraete, M.M., Antunes, M., Bacour, C., Gascon, F., GastelluEtchegorry, J.P., Jacquemoud, S., North, P., Qin, W., Thompson, R., 2001. Radiation transfer model intercomparison (RAMI) exercice. J. Geophys. Res. 106 (D11), 11937-11956.

Pinty, B., Widlowski, J.L., Taberner, M., Gobron, N., Verstraete, M.M., Disney, M., Gascon, F., Gastellu, J.P., Jiang, L., Kuusk,
A., Lewis, P., Li, X., Ni-Meister, W., Nilson, T., North, N., Qin, W., Su, L., Tang, S., Thompson, R., Verhoef, W., Wang, H., Wang, J., Yan, G., Zang, H., 2004. Radiation transfer model intercomparison (RAMI) exercice-2nd phase. J. Geophys. Res. 109 (D16), D06210.

Privette, J.L., Myneni, R.B., Tucker, C.J., Emery, W.J., 1994. Invertibility of a 1D discrete ordinates canopy reflectance model. Remote Sens. Environ. 105, 48-89.

Roujean, J.-L., Breon, F.-M., 1995. Estimating PAR absorbed by vegetation from bidirectional reflectance measurements. Remote Sens. Environ. 51, 375-384.

Verhoef, W., 1984. Light scattering by leaf layers with applications to canopy reflectance modeling: the SAIL model. Remote Sens. Environ. 16, 125-141.

Weiss, M., Baret, F., 1999. Evaluation of canopy biophysical variable retrieval performances from the accumulation of large swath satellite data. Remote Sens. Environ. 70, 293306.

Weiss, M., Baret, F., Myneni, R.B., Pragnère, A., Knyazikihn, Y., 2000. Investigation of a model inversion technique to estimate canopy biophysical variables from spectral and directional reflectance data. Agronomie 20, 3-22.

Weiss, M., Baret, F., Garrigues, S., Lacaze, R., 2007. LAI and fAPAR CYCLOPES global products derived from VEGETATION. Part 2: validation and comparison with MODIS collection 4 products. Remote Sens. Environ. 110, 317-331.

Welles, J.M., Norman, J.M., 1991. Instrument for indirect measurement of canopy architecture. Agron. J. 83, 818-825.

Widlowski, J.-L., Taberner, M., Pinty, B., Bruniquel-Pinel, V., Disney, M., Fernandes, R., Gastellu-Etchegorry, J.-P., Gobron, N., Kuusk, A., Lavergne, T., Leblanc, S., Lewis, P. E., Martin, E., Mõttus, M., North, P. R. J., Qin, W., Robustelli, M., Rochdi, N., Ruiloba, R., Soler, C., Thompson, R., Verhoef, W., Verstraete, M.M., Xie, D., 2007. Third Radiation Transfer Model Intercomparison (RAMI) exercise: Documenting progress in canopy reflectance models, J. Geophys. Res. Vol. 112, D09111, doi:10.1029/2006JD007821. 